\title{
Enhancing the Kinetic Stability of Polymeric Nano-micelles (PLGA) Using Nano- Montmorillonite for Effective Targeting of Cancer Tumors
}

Deniz Karataş ${ }^{a}$, Fatemeh Bahadori $^{b}$,, Adem Tekin ${ }^{c}$, Gamze Ergin Kizilcay ${ }^{d}$, Mehmet Sabri Celik $^{a}$

a Istanbul Technical University, Mineral Processing Engineering Department, 34469, Maslak, Turkey.

${ }^{b}$ Bezmialem Vakif University, Faculty of Pharmacy, Department of Pharmaceutical Biotechnology, 34093 Fatih, Turkey,fbahadori@bezmialem.edu.tr

${ }^{c}$ Istanbul Technical University, Informatics Institute, 34469 Maslak, Turkey

${ }^{d}$ Istanbul University, Faculty of Pharmacy, Department of Analytical Chemistry, 34116, Beyazit, Istanbul, Turkey

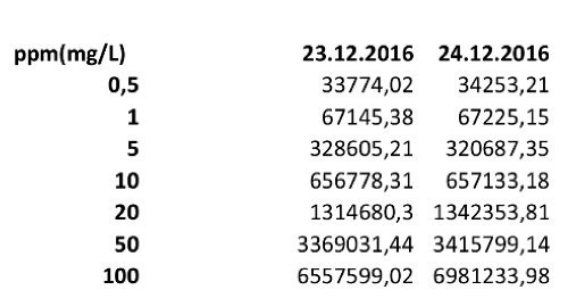

AUC
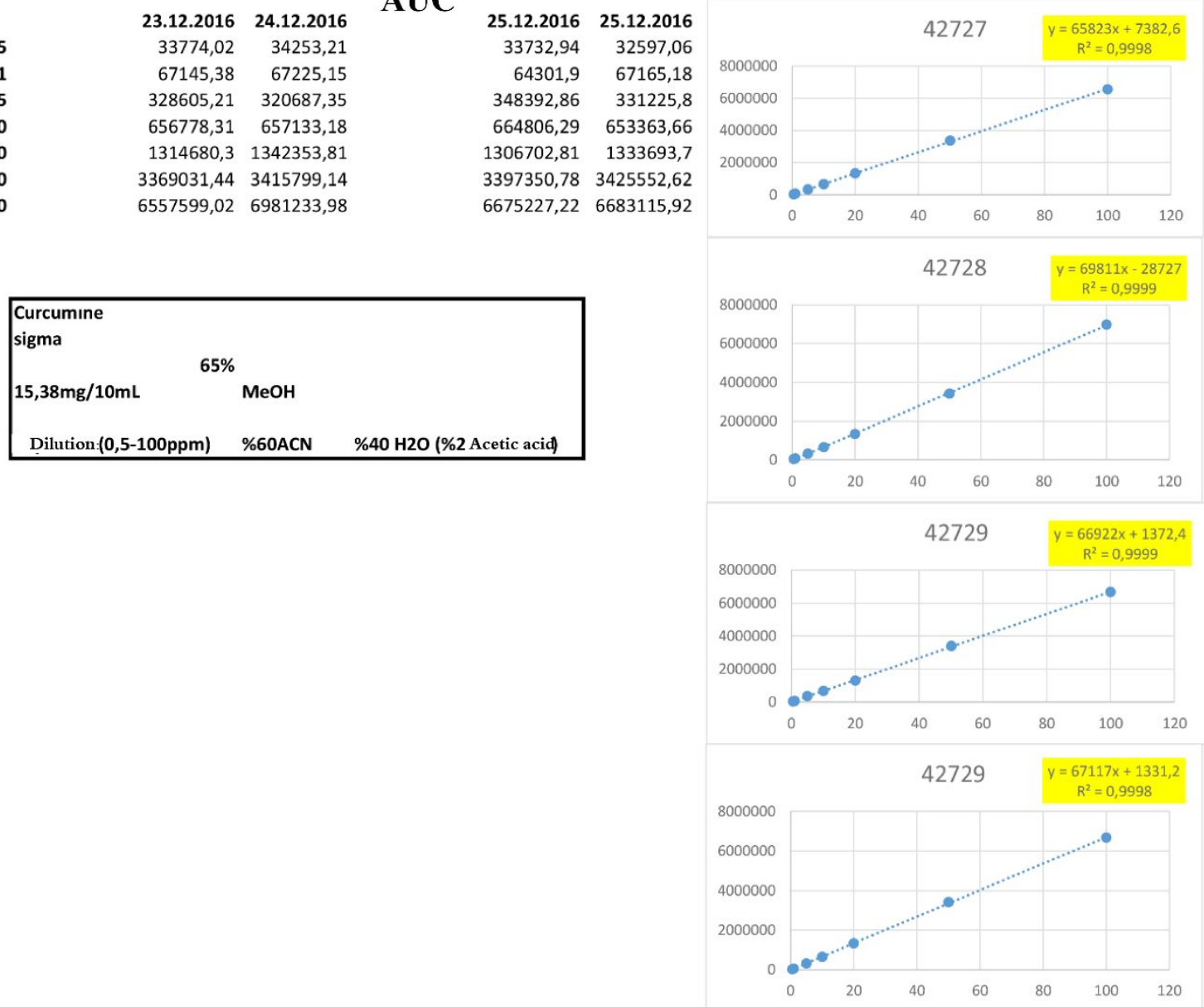

Figure SP1: The method validation has been carried out for the measurement method of curcumin in HPLC, and the standard curves obtained on 4 different days 


$\begin{array}{rlllll} & & & \text { Diam. (nm) } & \text { \% Volume } & \text { Width (nm) } \\ \text { Z-Average (d.nm): } & 184.5 & \text { Peak 1: } & 198.1 & 34.0 & 87.78 \\ \text { Pdl: } & 0.256 & \text { Peak 2: } & 5206 & 66.0 & 752.1 \\ \text { Intercept: } & 0.957 & \text { Peak 3: } & 0.000 & 0.0 & 0.000\end{array}$

Result quality : Good

Size Distribution by Volume

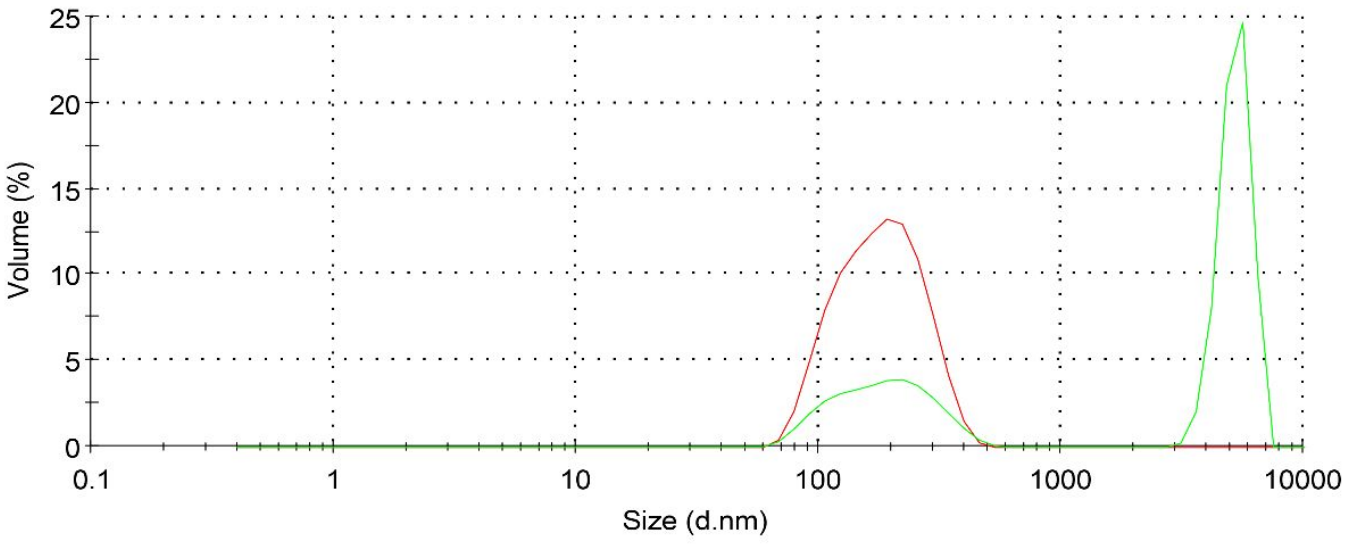

a

Z-Average (d.nm): 163.9

Pdl: 0.181

Intercept: 0.972

$\begin{array}{llll} & \text { Diam. }(\mathbf{n m}) & \text { \% Volume } & \text { Width }(\mathbf{n m}) \\ \text { Peak 1: } & 199.5 & 100.0 & 124.2 \\ \text { Peak 2: } & 0.000 & 0.0 & 0.000 \\ \text { Peak 3: } & 0.000 & 0.0 & 0.000\end{array}$

Result quality : Good

Size Distribution by Volume

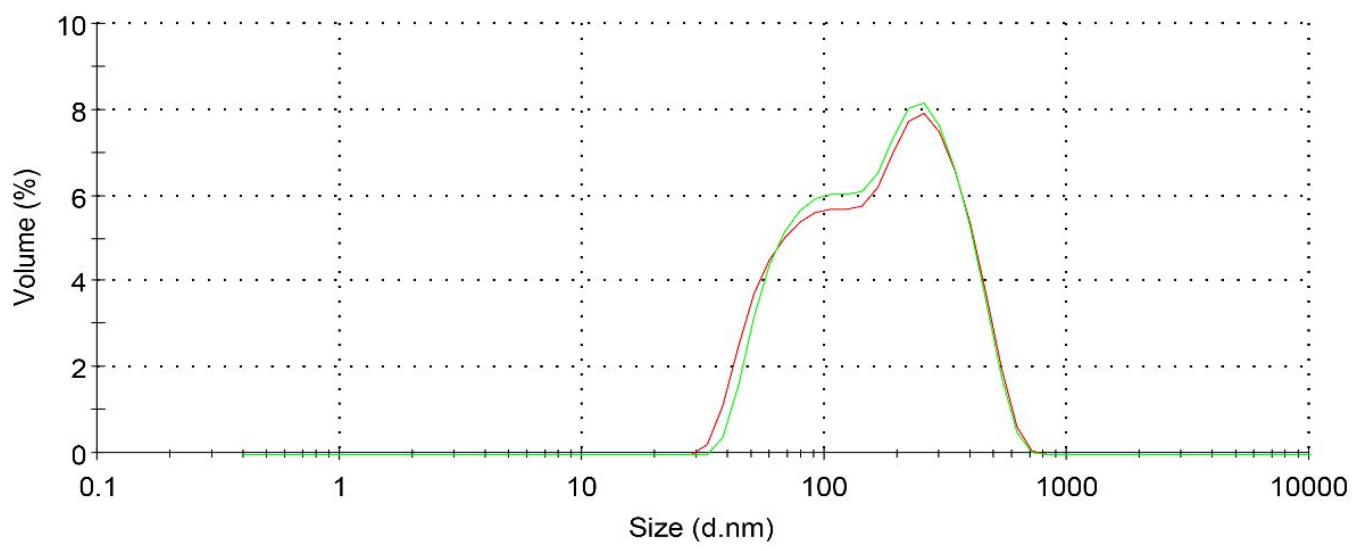

b

Figure SP2: The sizes of Na-MMT particles at the end of 1 and 2,5 hours processing in attritor 


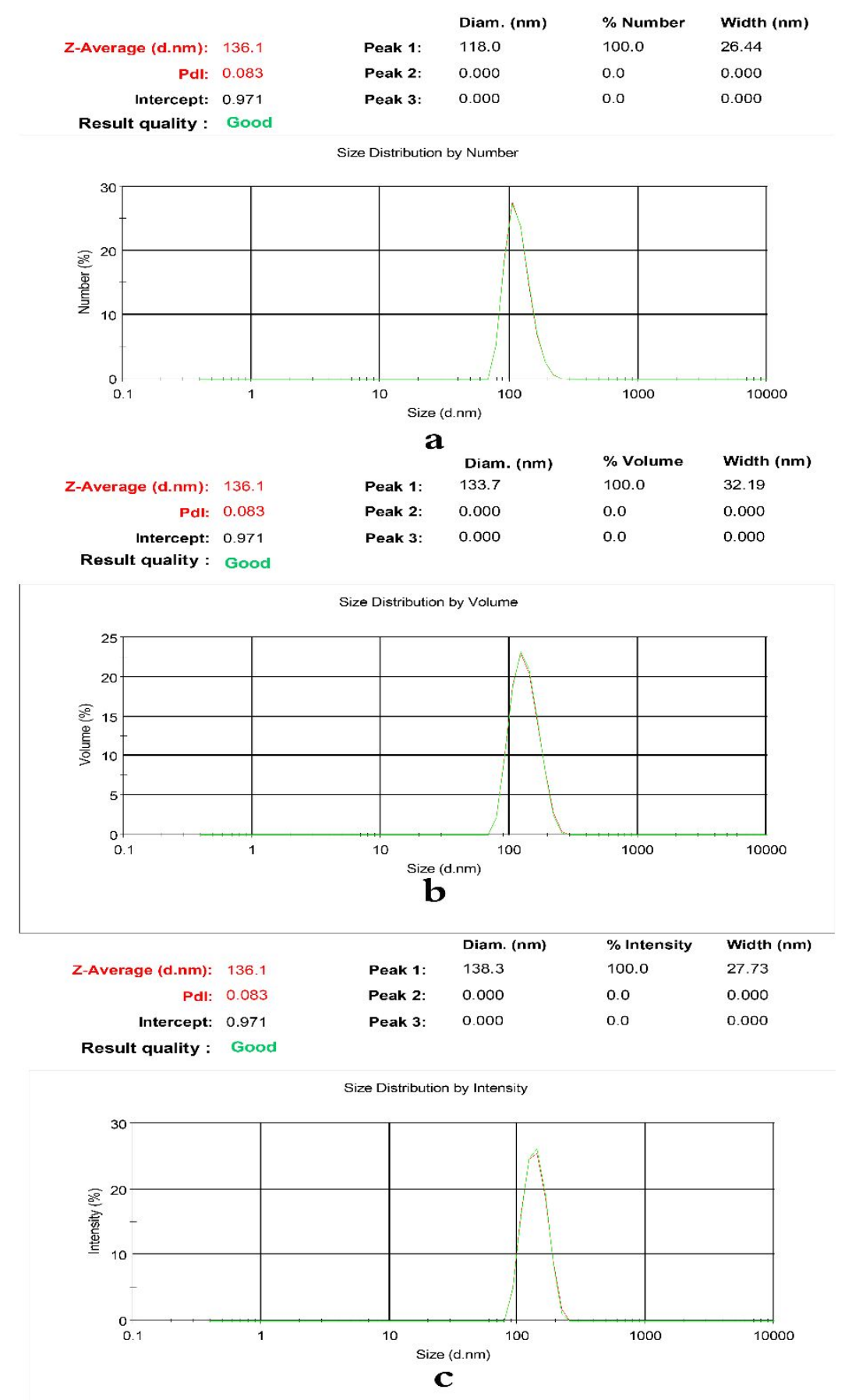

Figure SP3: Particle size distribution of PMC containing $500 \mu \mathrm{g}$ curcumin with the size distribution of a) number, $118 \mathrm{~nm}, \mathrm{~b}$ ) volume, $134 \mathrm{~nm}$, and c) intensity $138 \mathrm{~nm}$. 


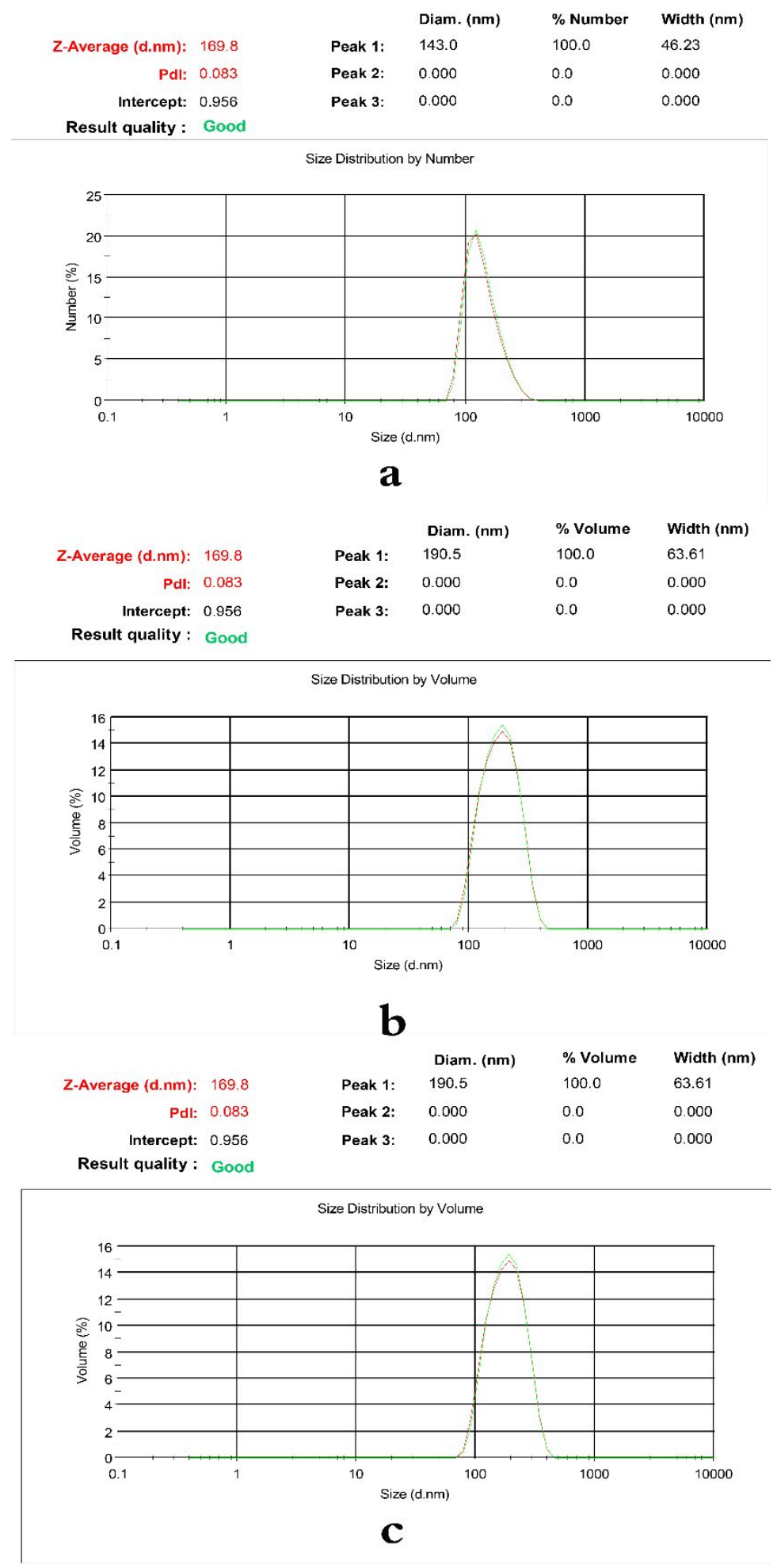

Figure SP4-1: Particle size distribution of PLGA NPs as a) number, $143 \mathrm{~nm}, \mathrm{~b}$ ) volume, 190 $\mathrm{nm}$, and c) intensity $184 \mathrm{~nm}$ with Z-average of 169,8 . 


\begin{tabular}{rlllll} 
& & & Diam. (nm) & $\%$ Number & Width (nm) \\
Z-Average (d.nm): & 95.65 & Peak 1: & 69.58 & 100.0 & 18.42 \\
Pdl: & 0.097 & Peak 2: & 0.000 & 0.0 & 0.000 \\
Intercept: & 0.973 & Peak 3: & 0.000 & 0.0 & 0.000 \\
Result quality : Good & & & & \\
\hline
\end{tabular}
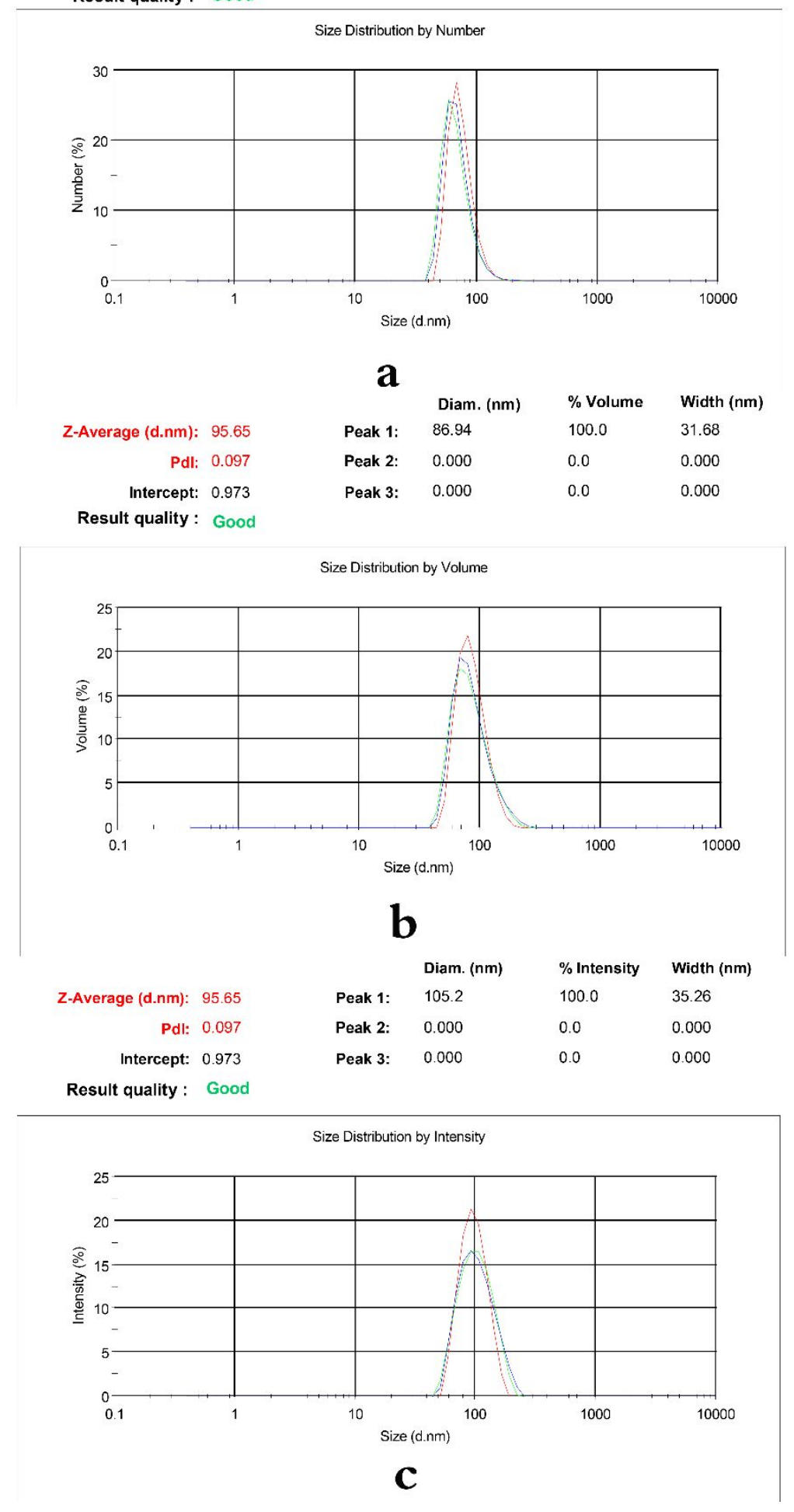

Figure SP4-2: Particle size distribution of PM with the size distribution of a) number, $70 \mathrm{~nm}, \mathrm{~b}$ ) volume, $87 \mathrm{~nm}$, and c) intensity $105 \mathrm{~nm}$ with Z-average of 95,65. 